\title{
Numerical simulation analysis of flow patterns and particle transport in the HEAD laser ablation cell with respect to inductively coupled plasma spectrometry $\dagger$
}

\author{
Received 7th October 2009, Accepted 28th January 2010 \\ First published as an Advance Article on the web 4th February 2010 \\ DOI: $10.1039 / \mathrm{b} 920905 \mathrm{k}$
}

Helmut Lindner, ${ }^{* a}$ David Autrique, ${ }^{a}$ Jorge Pisonero, ${ }^{b}$ Detlef Günther ${ }^{c}$ and Annemie Bogaerts ${ }^{a}$

The present study analyses a specific laser ablation cell, the High Efficiency Aerosol Dispersion (HEAD) cell (see J. Pisonero et al., J. Anal. At. Spectrom., 2006, 21, 922-931), by means of computational fluid dynamics (CFD) simulations. However, this cell consists of different modular parts, therefore, the results are probably of interest for the further development of other ablation cells. In the HEAD cell, the ablation spot is positioned below an orifice in the ceiling of the sample chamber. The particle transport through this orifice has been analysed for a ceiling height of $0.8 \mathrm{~mm}$. The critical velocity for the onset of particle losses was found to be independent on the ejection angle at the crater spot. The deceleration of the particles can be described as the stopping in an effectively steady gas. Particle losses were negligible in this modular part of the cell at the evaluated laser ablation conditions. The transport efficiency through the Venturi chamber was investigated for different sample gas flow rates. In this case, it was found that small particles were predominantly lost at low flow rates, the large particles at higher flow rates. Making use of the simulation results, it was possible to design a modification of the HEAD cell that results in extremely short calculated washout times. The simulations yielded a signal of less than $10 \mathrm{~ms}$, which was produced by more than $99 \%$ of the introduced mass.

\section{Introduction}

Laser ablation inductively coupled plasma mass spectrometry (LA-ICP-MS) is a widely used technique for elemental analysis. It is a very sensitive technique that can be used for the direct analysis of a wide range of very different materials such as metals, glasses or geological samples, see e.g. ref. 1,2,3. There is no or only little sample preparation required for the analysis of the sample. LA-ICP-MS can be used to quantify major, minor and trace constituents of the sample, see e.g. ref. 4,5. Since a good spatial resolution (few $\mu \mathrm{m}$ in lateral direction and several hundred $\mathrm{nm}$ in depth) can be achieved in LA, it is used for spatial mapping investigations such as line scans of e.g. blotmembranes ${ }^{6}$ or elemental depth-profiling of coatings. ${ }^{7}$

Due to the wide applicability, much work has been carried out in order to understand and improve this analytical method. In this sense, past research investigated the laser ablation process itself, the composition and the size-distribution of laser-induced particles, the reduction of elemental fractionation effects, and

${ }^{a}$ PLASMANT, Department of Chemistry, University of Antwerp, Universiteitsplein 1, 2610 Antwerp, Belgium.E-mail: helmut.lindner@ua. ac.be

${ }^{b}$ Department of Physics, University of Oviedo, clGonzalo Gutierrez Quiros, Campus de Mieres, 33600 Mieres, Spain

${ }^{c}$ Laboratory for Inorganic Chemistry, Department of Chemistry and Applied Biosciences, ETH Zürich, Wolfgang-Pauli-Straße 10, 8093 Zürich, Switzerland

$\dagger$ This article is part of a themed issue devoted to highlighting the work of outstanding young analytical scientists (YAS) working in the area of analytical atomic spectrometry. This 3rd YAS issue has been guest edited by Professor Spiros Pergantis. also the particle transport to the ICP (see the survey articles ref. 8,9 and references therein). The overall transport efficiency in fslaser ablation was found to be more than $80 \%$ for different ablation cells using helium or argon as transport gas. ${ }^{10,11}$ Spatial mapping analyses require the correlation between laser spot and signal. Therefore, many laser shots are required but the measured signals related to successive laser shots need to be separated from each other. In order to be able to reduce measurement time, laser ablation cells and setups were optimized in terms of short washout times. Signal durations were achieved down to about $100 \mathrm{~ms}$ using a $10 \%$ signal-height ${ }^{12}$ and $140 \mathrm{~ms}$ using a $3 \%$ signalarea criterion. ${ }^{13}$ The lateral material distribution at the end of a transport tube was explored by means of light scattering by laser produced particles ${ }^{15}$ for laminar as well as turbulent flow in the laser ablation cell. The initial radial concentration distribution was reconstructed from an ICP-MS signal ${ }^{13}$ for a sampling tube laser ablation cell, having laminar flow throughout the whole transport system.

Computational fluid dynamics (CFD) is a powerful tool to analyze the behaviour of various flow systems, as for instance laser ablation cells. The investigations in ref. 16 analyzed effects of particle extraction in dependence on the geometry of different kinds of 'drum'-shaped laser ablation cells. In ref. 17, a full transport setup, consisting of a sampling-tube ablation cell and the transport tubing, was modelled. A good agreement between simulated and experimental results was found. The simulation indicated critical structures in the transport way that had strong influence on the resulting signal. From this knowledge, an improved and well understood setup was attained. ${ }^{13}$ 
In the present study, we use CFD simulations to obtain results that for various reasons, such as availability of adequate reference materials or applicable measurement methods, are hardly accessible by experiments. The High Efficiency Aerosol Dispersion (HEAD) laser ablation cell, first presented in ref. 14, was the subject of this study. It is a nice object of study since it consists of quite different modular parts so the respective results can also be used for other laser ablation setups and for optimizations.

In the first part of the article, the HEAD cell and the simulation background will be presented. This will be followed by the simulation results on the present setup. Finally, one modification of the cell, which was designed based on the results from the analysis of the HEAD cell, will be displayed.

\section{The HEAD ablation cell}

A scheme of the HEAD-ablation cell is shown in Fig. 1. The cell consists of three main regions. The sample is situated in the 'sample chamber' at the bottom of the cell. This chamber is separated from the next part of the cell, the 'central chamber', by a flat wall and only an orifice allows the gas to flow from the sample chamber into the central chamber. The height of the sample chamber can be adjusted so that a defined distance between sample surface and ceiling can be set.

A small inlet for introducing optional gas is present between sample chamber and central chamber. When closed, as it was the case, it has no influence on the flow behaviour, as can be seen below.

The central chamber opens conically in the axial direction into a cylindrical volume after the orifice. The laser beam enters this chamber at the top side through a window and passes through the orifice to ablate the sample. The outlet of the central chamber is positioned tangentially to the cylinder in the upper part of the chamber.

The outlet leads to the third part of the cell, the Venturi chamber. Here, two nozzles are positioned perpendicular to each other. The sample gas (containing the aerosol) is introduced into the carrier gas stream under an angle of 90 degrees. The carrier gas flows straight to the outlet.

\section{Simulation setup}

To model the HEAD cell, the flow relevant dimensions were transferred from the blueprint to a computation geometry using the computer program Gambit (ANSYS). The created geometry was subdivided into 2.3 million control volumes. The computational fluid dynamics (CFD) program Fluent (ANSYS) was used for the simulations. The so-called 'realizable $k-\varepsilon$ model' (see below) was applied to calculate the flow inside the cell.

Additionally, the Venturi chamber was modeled separately to obtain better insight into this region. For these investigations, the Venturi chamber together with the outlet tube was divided into 2 million control volumes. Here, the Reynolds-stress model (see below) was used.

At the inlet of the sample chamber, pure helium was introduced into the cell. The applied flow rates matched a range of 5 to $1000 \mathrm{~mL} / \mathrm{min}$ helium. At the carrier gas inlet, pure argon was added at a flow rate of $1.1 \mathrm{~L} / \mathrm{min}$. The flow rates were chosen based on the ones used in ref. 14,18.

Particles were tracked taking into account the Cunninghamcorrection and Brownian motion (see below). They were modeled as uniform sized copper-particles in the diameter range of $10 \mathrm{~nm}$ to $1 \mu \mathrm{m}$. The influence of such particles on the gas flow under the present conditions is negligible and has therefore not been taken into account. The Van der Waals interaction of the particles with a wall is strong. ${ }^{19}$ Consequently, particles were treated as 'lost' when they hit a wall.

\subsection{Flow calculation}

Two different turbulence models have been applied to calculate the flow patterns. For the whole ablation cell, the realizable $k$ - $\varepsilon$ model was used. It belongs to the group of Reynolds-averaged Navier-Stokes (RANS) models. The RANS-equation ${ }^{20}$ for steady state is given by

$$
\begin{aligned}
\frac{\partial}{\partial x_{j}}\left(\rho u_{i} u_{j}\right)= & -\frac{\partial p}{\partial x_{i}}+\frac{\partial}{\partial x_{j}}\left[\mu\left(\frac{\partial u_{i}}{\partial x_{j}}+\frac{\partial u_{j}}{\partial x_{i}}-\frac{2}{3} \delta_{i j} \frac{\partial u_{l}}{\partial x_{l}}\right)\right] \\
& +\frac{\partial}{\partial x_{j}}\left(-\rho \overline{u_{i}^{\prime} u_{j}^{\prime}}\right)
\end{aligned}
$$

where $u$ is the time-averaged gas velocity, $u_{i}^{\prime}$ are zero-mean velocity fluctuations, $\mu$ is the dynamic viscosity and $-\rho \overline{u_{i}^{\prime} u_{j}^{\prime}}$ are the Reynolds-stresses. $p$ is the pressure. The indices $i, j$ and $l$ denote the spatial direction, each taking the values $x, y$ or $z$. If an index is present twice within one term, then it is summed over the possible states (also in the following). $\delta_{i j}$ is the Kronecker delta which is 1 for $i=j$ and 0 otherwise. The turbulent kinetic energy $k$ is calculated from the equation

$$
\frac{\partial}{\partial x_{j}}\left(\rho k u_{j}\right)=\frac{\partial}{\partial x_{j}}\left[\left(\mu+\frac{\mu_{t}}{\sigma_{k}}\right) \frac{\partial k}{\partial x_{j}}\right]+G_{k}-\rho \varepsilon\left(1+2 \frac{k}{a^{2}}\right)
$$
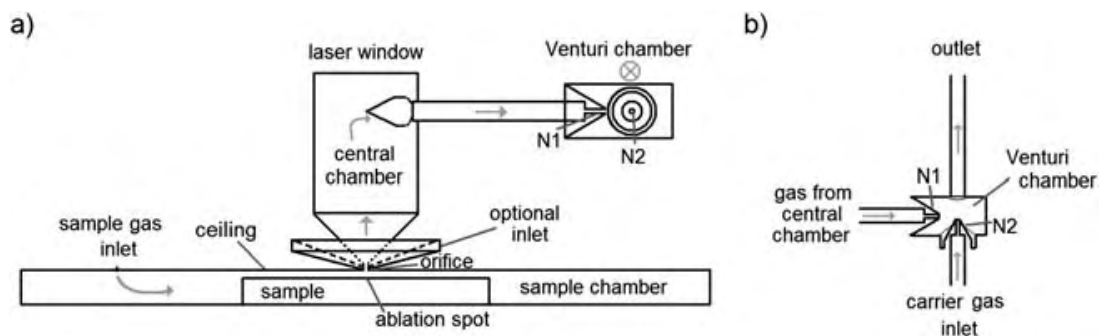

Fig. 1 Scheme of the flow relevant regions of the HEAD cell in side view, a). The top view of the Venturi chamber is displayed in b). The light gray arrows denote the gas flow direction. N1, N2 mean nozzle 1 and nozzle 2, respectively. The scheme is in scale and the diameter of the sample chamber is 7 $\mathrm{cm}$. Hidden parts are denoted by dashed lines. 
where $a$ is the speed of sound. The production of turbulent kinetic energy $G_{k}$ is given by

$$
G_{k}=\mu_{t} S^{2}
$$

with the turbulent viscosity $\mu_{t}$ being calculated from

$$
\mu_{t}=\rho C_{\mu} \frac{k^{2}}{\varepsilon}
$$

The turbulent dissipation rate $\varepsilon$ is determined from

$$
\frac{\partial}{\partial x_{j}}\left(\rho \varepsilon u_{j}\right)=\frac{\partial}{\partial x_{j}}\left[\left(\mu+\frac{\mu_{t}}{\sigma_{\varepsilon}}\right) \frac{\partial \varepsilon}{\partial x_{j}}\right]+\rho C_{1} S \varepsilon-\rho C_{2} \frac{\varepsilon^{2}}{k+\sqrt{\nu \varepsilon}}
$$

See also Table 1 for the further parameters.

For the Venturi chamber the Reynolds-stress model (RSM) was applied, as mentioned above. This model also belongs to the RANS models. Thus, eqn (1) is also used here. However, the Reynolds-stresses are calculated separately. Therefore, it is computationally more expensive but it can deal better with swirling flows. ${ }^{20}$ To determine the Reynolds stresses, the following equations are solved

$$
C_{i j}=D_{T, i j}+D_{L, i j}+P_{i j}+\Phi_{i j}+\varepsilon_{i j}
$$

Here, $C_{i j}$ denotes convection, $D_{T, i j}$ turbulent diffusion, $D_{L, i j}$

\begin{tabular}{|c|c|c|}
\hline Parameter & realizable $k-\varepsilon$ model & RSM \\
\hline$\sigma_{k}$ & 1 & 0.82 \\
\hline$\sigma_{\varepsilon}$ & 1.2 & 1 \\
\hline$C_{1}$ & $\max \left[0.43, \frac{\eta}{\eta+5}\right]$ & - \\
\hline$C_{\varepsilon 1}$ & - & 1.44 \\
\hline$C_{2}$ & 1.9 & - \\
\hline$C_{\varepsilon 2}$ & - & 1.92 \\
\hline$C_{\mu}$ & $\left(4.04+A_{s} \frac{k S}{\sqrt{2} \varepsilon}\right)^{-1}$ & 0.09 \\
\hline$S_{i j}$ & $\frac{1}{2}\left(\frac{\partial u_{i}}{\partial x_{j}}+\frac{\partial u_{j}}{\partial x_{i}}\right)$ & - \\
\hline$S$ & $\sqrt{2 S_{i j} S_{i j}}$ & - \\
\hline$\eta$ & $S \frac{k}{\varepsilon}$ & - \\
\hline$A_{s}$ & $\sqrt{6} \cos \left(\frac{1}{3} \cos ^{-1}\left(\sqrt{48} \frac{S_{i j} S_{j k} S_{k i}}{S^{3}}\right)\right)$ & - \\
\hline
\end{tabular}
molecular diffusion, $P_{i j}$ stress production, $\Phi_{i j}$ pressure strain and $\varepsilon_{i j}$ denotes dissipation. Eqn (6) can be written as

Table 1 Parameters used for the turbulent models

$$
\begin{aligned}
\frac{\partial}{\partial x_{k}}\left(\rho u_{k} \overline{u_{i}^{\prime} u_{j}^{\prime}}\right)= & -\frac{\partial}{\partial x_{k}}\left(\rho \overline{u_{i}^{\prime} u_{j}^{\prime} u_{k}^{\prime}}+\overline{p\left(\delta_{k j} u_{i}^{\prime}+\delta_{i k} u_{j}^{\prime}\right)}\right) \\
& +\frac{\partial}{\partial x_{k}}\left[\mu \frac{\partial}{\partial x_{k}}\left(\overline{u_{i}^{\prime} u_{j}^{\prime}}\right)\right]-\rho\left(\overline{\bar{u}_{i}^{\prime} u_{k}^{\prime}} \frac{\partial u_{j}}{\partial x_{k}}+\overline{u_{j}^{\prime} u_{k}^{\prime}} \frac{\partial u_{i}}{\partial x_{k}}\right) \\
& +p \overline{\left(\frac{\partial u_{i}^{\prime}}{\partial x_{j}}+\frac{\partial u_{j}^{\prime}}{\partial x_{i}}\right)}-2 \mu \frac{\partial \frac{u_{i}^{\prime}}{\partial x_{k}} \frac{\partial u_{j}^{\prime}}{\partial x_{k}}}{}
\end{aligned}
$$

The terms $D_{T, i j}, \Phi_{i j}$ and $\varepsilon_{i j}$ in eqn (7) require some further assumptions to close the equations. Fluent uses the following approximation for the turbulent diffusion

$$
D_{T, i j}=\frac{\partial}{\partial x_{k}}\left(\frac{\mu_{t}}{\sigma_{k}} \frac{\partial \overline{u_{i}^{\prime} u_{j}^{\prime}}}{\partial x_{k}}\right)
$$

The pressure strain $\Phi_{i j}$ is modelled using a linear model taking into account slow pressure strain $\Phi_{i j, 1}$, rapid pressure strain $\Phi_{i j, 2}$ and wall-reflection $\Phi_{i j, w}$ in the form

$$
\Phi_{i j}=\Phi_{i j, 1}+\Phi_{i j, 2}+\Phi_{i j, 3}
$$

with

$$
\Phi_{i j, 1}=-1.8 \cdot \rho \frac{\varepsilon}{k}\left[\overline{u_{i}^{\prime} u_{j}^{\prime}}-\frac{2}{3} \delta_{i j} k\right]
$$

$$
\begin{gathered}
\Phi_{i j, 2}=-0.6\left[\left(P_{i j}-C_{i j}\right)-1 / 3 \delta_{i j}\left(P_{k k}-C_{k k}\right)\right] \\
\Phi_{i j, w}=0.5 \cdot \frac{\varepsilon}{k}\left(-\frac{3}{2} \overline{u_{i}^{\prime} u_{k}^{\prime}} n_{j} n_{k}-\frac{3}{2} \overline{u_{j}^{\prime} u_{k}^{\prime}} n_{i} n_{k}\right) \frac{0.3924 \cdot k^{3 / 2}}{\varepsilon d} \\
+0.3 \cdot\left(-\frac{3}{2} \Phi_{i k, 2} n_{j} n_{k}-\frac{3}{2} \phi_{j k, 2} n_{i} n_{k}\right) \frac{0.3924 \cdot k^{3 / 2}}{\varepsilon d}
\end{gathered}
$$

$d$ is the normal distance to the wall, $n_{k}$ and $x_{k}$ are the component of the unit normal to the wall. The turbulent kinetic energy used in the volume is

$$
k=\frac{1}{2} \overline{u_{i}^{\prime} u_{i}^{\prime}}
$$

The Reynolds-stresses at the wall boundary are computed from

$$
\frac{\overline{u_{\tau}^{\prime 2}}}{k}=1.098, \frac{\overline{u_{\eta}^{\prime 2}}}{k}=0.247, \frac{\overline{u_{\lambda}^{\prime 2}}}{k}=0.655, \frac{\overline{u_{\tau}^{\prime} u_{\eta}^{\prime}}}{k}=-0.255
$$

where $\tau, \eta$ and $\lambda$ denote the local tangential, normal and binormal coordinate at the wall, respectively. To obtain $k$ at the boundary, the equation

$$
\frac{\partial}{\partial x_{i}}\left(\rho k u_{i}\right)=\frac{\partial}{\partial x_{j}}\left[\left(\mu+\frac{\mu_{t}}{\sigma_{k}}\right) \frac{\partial k}{\partial x_{j}}\right]+\frac{1}{2} P_{i i}-\rho \varepsilon\left(1+2 \frac{k}{a^{2}}\right)
$$

is solved. The dissipation tensor is modeled from

$$
\varepsilon_{i j}=\frac{2}{3} \rho \varepsilon\left(1+2 \frac{k}{a^{2}}\right) \delta_{i j}
$$

where the scalar dissipation rate $\varepsilon$ is calculated from 


$$
\frac{\partial}{\partial x_{i}}\left(\rho \varepsilon u_{i}\right)=\frac{\partial}{\partial x_{j}}\left[\left(\mu+\frac{\mu_{t}}{\sigma_{\varepsilon}}\right) \frac{\partial \varepsilon}{\partial x_{j}}\right] C_{\varepsilon 1} \frac{1}{2} P_{i i} \frac{\varepsilon}{k}-C_{\varepsilon 2} \rho \frac{\varepsilon^{2}}{k}
$$

\subsection{Particle tracking}

Particles have been tracked using the so-called discrete phase model (DPM) of Fluent. ${ }^{20}$ Most laser produced particles are in the size range below $1 \mu \mathrm{m}$ diameter. ${ }^{21,22,23}$ For such particles, a slip correction has to be applied for the fact that the mean free path $\lambda$ inside the gas becomes similar to the particle diameter $d_{p}$. The correction used for this purpose is the Cunningham slip factor $C_{c}$

$$
C_{c}=1+2 \frac{\lambda}{d_{p}}\left(1.257+0.4 \cdot \exp \left(\frac{1.1 \cdot d_{p}}{2 \lambda}\right)\right)
$$

which is introduced into the drag law

$$
\frac{d u_{p}}{d t}=\frac{18 \mu}{\rho_{p} d_{p}^{2} C_{c}}\left(u-u_{p}\right)
$$

where $u$ is the gas velocity and $u_{p}$ is the particle velocity. $\rho_{p}$ is the particle density and $\mu$ is the dynamic viscosity.

The Brownian motion has been taken into account. This is modeled as a Gaussian white noise process. It has the spectral intensity

$$
\tilde{S}_{n, i j}=\tilde{S}_{0} \delta_{i j}
$$

with

$$
\tilde{S}_{0}=\frac{216 v k_{B} T}{\pi^{2} \rho d_{p}^{5}\left(\frac{\rho_{p}}{\rho}\right)^{2} C_{c}}
$$

$\nu$ is the kinematic viscosity, $\rho$ the gas density, $T$ the absolute temperature and $k_{B}$ is the Boltzmann constant. The force is given by

$$
F_{b i}=\zeta_{i} \sqrt{\frac{\pi \tilde{S}_{0}}{\Delta t}}
$$

where $\zeta_{i}$ are zero-mean, Gaussian random numbers.

\section{Results and discussion}

As has been mentioned above, the HEAD cell can be regarded as consisting of three parts, namely the sample chamber, the central chamber and the Venturi chamber. These three parts will also be presented separately. The presentation follows the way of transportation, beginning with the sample chamber, continuing with the central chamber and finishing with the Venturi chamber. Furthermore, one possible modification of the HEAD cell will be presented.

\subsection{Sample chamber}

The sample is placed in the center of the sample chamber. The ablation spot is directly opposed to the orifice through which the laser beam enters the chamber, see Fig. 1. The sample gas enters through the gas inlet in the ceiling at an outer position of the chamber, see Fig. 2. The gas fills the chamber and, above the
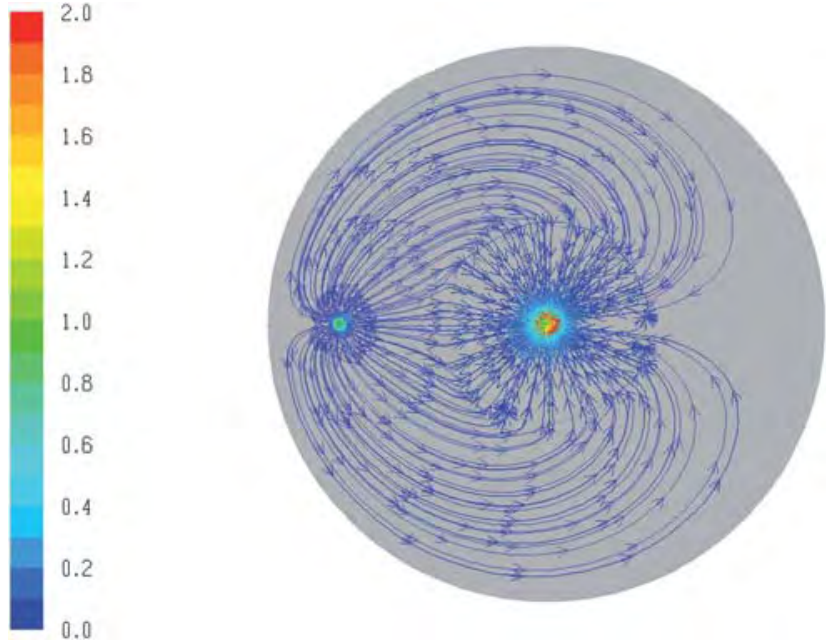

Fig. 2 Flow patterns inside the sample chamber (top view), colored by velocity magnitude in $\mathrm{m} / \mathrm{s}$. The spot in the center denotes the orifice position, where also the ablation spot is situated. The other spot on the left is the gas inlet position.

sample, it flows in radial direction towards the ablation spot. There it leaves through the orifice in the ceiling.

The distance between sample and ceiling was $0.8 \mathrm{~mm}$ as in ref. 14. This distance is rather short. Consequently, an important question is whether the particles created in the laser ablation process will leave the chamber through the orifice without significant losses. To investigate that, particles were released from a spot of $70 \mu \mathrm{m}$ diameter located at the sample site and in the center of the chamber. The effect of different opening angles relative to the ablation axis was studied as well as different initial particle velocities.

In Fig. 3, particle tracks above the sample are shown for particles of $1 \mu \mathrm{m}$ diameter. They were released under a maximum opening angle of 30 degrees relative to the axis normal to the sample surface and with an initial velocity of $10 \mathrm{~m} / \mathrm{s}$. The particles first fly away from each other as expected. After a while, they

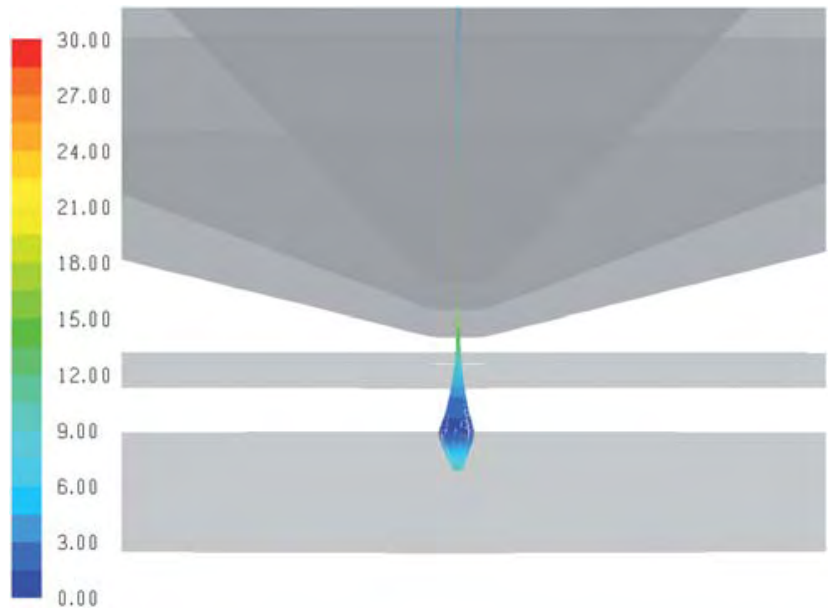

Fig. 3 Tracks of particles of $1 \mu \mathrm{m}$ diameter leaving the sample surface (bottom) and moving through the orifice in the ceiling into the central chamber; initial particle velocity: $10 \mathrm{~m} / \mathrm{s}$; opening angle: 30 degrees. The sample gas flow rate was $100 \mathrm{~mL} / \mathrm{min}$ helium. The tracks are colored by velocity magnitude in $\mathrm{m} / \mathrm{s}$. 


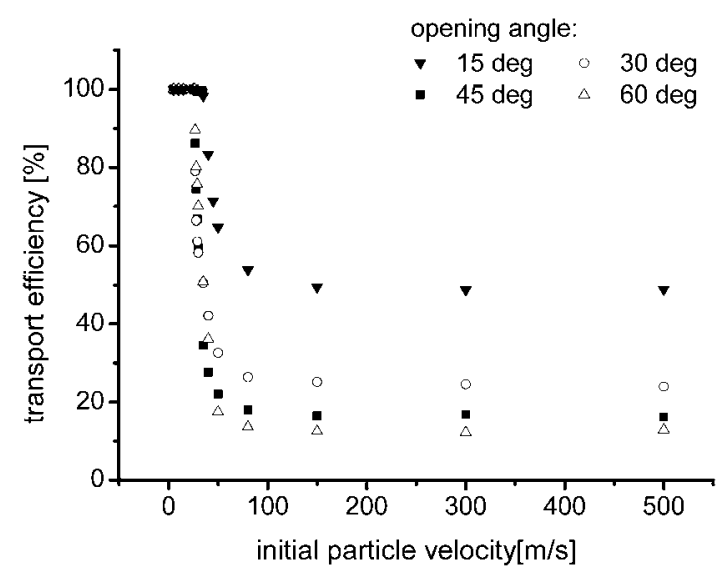

Fig. 4 Calculated transport efficiency of particles of $1 \mu \mathrm{m}$ diameter in dependence of the initial velocity for different opening angles, helium flow rate: $100 \mathrm{~mL} / \mathrm{min}$.

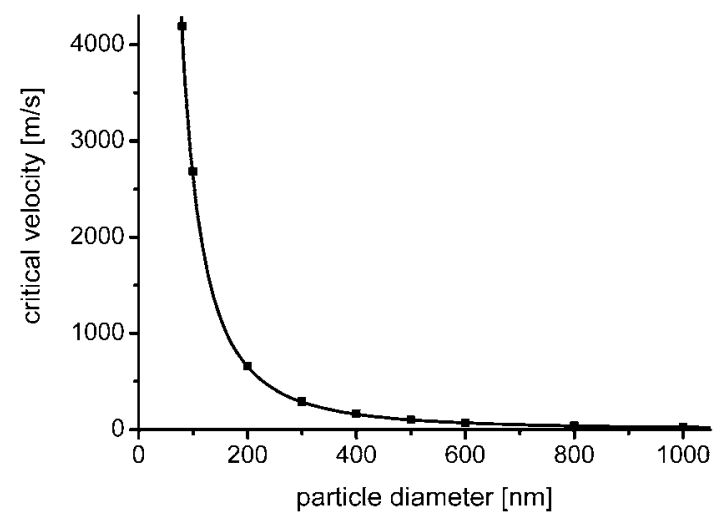

Fig. 5 Critical initial particle velocity (in $\mathrm{m} / \mathrm{s}$ ) for different particle diameters at a helium flow rate of $100 \mathrm{~mL} / \mathrm{min}$ and an opening angle of 30 degrees.

reach a maximum in sideward expansion. Then, they are transported back to the center by the gas flow and leave the sample chamber through the orifice in the ceiling.

In Fig. 4, the calculated transport efficiency through the orifice is plotted against the initial particle velocity. The particle diameter was $1 \mu \mathrm{m}$ and the helium flow rate was $100 \mathrm{~mL} / \mathrm{min}$. One can see that up to an initial particle velocity of $26 \mathrm{~m} / \mathrm{s}$, all particles were transported through the orifice independent of the opening angle. However, at higher initial particle velocities particles get lost. Indeed, particles at sufficiently high velocity follow a (nearly) straight path. This means that for larger opening angles, more particles hit the ceiling without passing through the orifice and the transport efficiency is reduced down to $10-50 \%$ depending on the opening angle.

In Fig. 5, the critical velocity, i.e. the velocity until which all particles are transported through the orifice, is displayed against particle diameter. The dependence has been found to be

$$
v_{0 c r i t} \propto \frac{1}{d_{p}^{2}}
$$

Hence, smaller particles can be transported with $100 \%$ efficiency until higher velocities.
The forces dominating the particle movement are the inertial force and the drag force. The stopping distance $\ell_{\max }$ for a particle with initial velocity $v_{0}$ moving against a gas stream of velocity $u$ can be calculated from eqn (19) to be

$$
\ell_{\text {max }}=\frac{m_{p}}{\alpha} v_{0}\left(1-\frac{u}{v_{0}}+\frac{u}{v_{0}} \ln \left(\frac{u}{v_{0}}\right)\right)
$$

with $m_{p}$ the particle mass and $\alpha$ the drag coefficient. The initial particle velocity $v_{0}$ is much higher than the gas velocity $u(\sim 1.7$ $\mathrm{m} / \mathrm{s}$ at $0.5 \mathrm{~mm}$ radius from ablation axis). Thus, the gas can be regarded as effectively steady and the terms containing $u / v_{0}$ in eqn (24) can be neglected. The initial particle velocity can then be calculated from

$$
v_{0} \approx \frac{18 \mu \ell_{\max }}{\rho_{p}} \frac{1}{d_{p}^{2}}
$$

Using the fit parameter $\left(26 \times 10^{-12} \mathrm{~m}^{3} / \mathrm{s}\right)$ from the curve in Fig. 5, the stopping distance was found to be $0.75 \mathrm{~mm}$. This is nearly the ceiling height. It has to be somewhat lower for no particle losses to occur since the gas still needs to transport the particles through the orifice after they stopped.

The critical velocity will not change tremendously if higher flow rates are applied. The particles still need to be stopped within a similar distance. However, the transport efficiency increases for velocities above the critical one if higher flow rates are applied. The outer particles stop at a lower height. Following the stream lines, they move through the orifice nearer to the center.

In ref. 24, initial particle velocities have been determined from particle visualization experiments. The values reported from measurements in argon were $11 \mathrm{~m} / \mathrm{s}$ and up to about three times more for ablation in helium. The angle was found to be between 15 and 30 degrees. Unfortunately, no information was given on the particle size dominating the figures. It is, however, likely that the scattering was dominated by particles in the size of several hundred $\mathrm{nm}$ diameter. On the one hand, scattering increases strongly with the particle size, but on the other hand, a sufficient number of particles must be present to produce a visible distribution. Therefore, we correlate the determined initial velocities with this particle size range. For particles of $500 \mathrm{~nm}$ diameter, the critical velocity was found to be more than $100 \mathrm{~m} / \mathrm{s}$, see Fig. 5 . For small particles, the critical velocity rises strongly and exceeds several thousand $\mathrm{m} / \mathrm{s}$, see Fig. 5. This means that they even may travel with the laser produced shock-wave without getting lost. Therefore, we conclude that in laser ablation, no significant particle loss will occur at the ceiling of the sample chamber.

\subsection{Central chamber}

The sample chamber is followed by the central chamber. The ablated material is pushed by the sample gas into the central chamber through the orifice in the bottom. The chamber opens conically and the outlet is placed tangentially to the cylindrical volume, see Fig. 1. The flushing is supported by the Venturi effect taking place in the Venturi chamber behind the central chamber. To investigate this 'pulling'-effect, the HEAD cell has been modelled with and without Venturi chamber.

In Fig. 6a, the streamlines inside the central chamber for the case without Venturi chamber are shown. As one can see, a backflow has evolved which is present up about half of the 

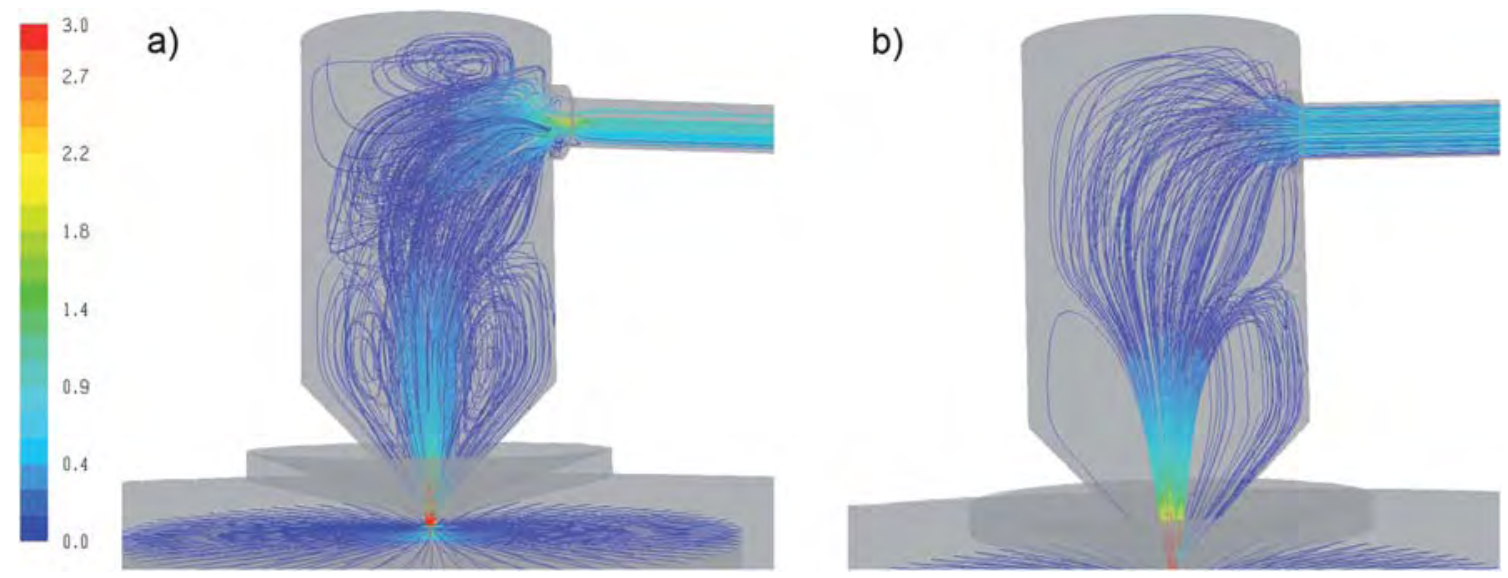

Fig. 6 Calculated flow lines inside the central chamber for a helium flow rate of $100 \mathrm{~mL} / \mathrm{min}$, a) without and b) with Venturi chamber following. The flow lines are colored by velocity magnitude in $\mathrm{m} / \mathrm{s}$.

chamber height. Above that region, the flow does not straightly flow out of the cell but is swirling. Some pathlines even enter the tube and return back to the chamber. If the Venturi chamber is used, these structures are removed and the pathlines directly leave the chamber. However, the backflow structures are still present but, nevertheless, they are not so numerous as in the case without Venturi chamber, cp. Fig. 6a and b. Note that in both pictures the same number of flow lines are displayed. The backflow is not critical since nearly all pathlines directly leave the chamber and the particles follow them. However, the pressure reduction produced by the Venturi chamber is not sufficient for higher sample gas flow rates. For e.g. $500 \mathrm{~mL} / \mathrm{min}$ helium, the backflow structure fills the whole central chamber.

In principle, the 'pulling'-effect could be increased by applying a higher flow rate at nozzle 2. However, the flow rate of $1.1 \mathrm{~L} / \mathrm{min}$ argon was chosen in the experiments ${ }^{14}$ to meet optimum flow conditions for the ICP. Therefore, this value was kept fixed in the calculations too.

\subsection{Venturi chamber}

In Fig. 7, the calculated flow lines inside the Venturi chamber are shown. The sample gas is introduced into the chamber from nozzle 1 on the left side while the carrier gas enters the chamber through nozzle 2 on the bottom side of the picture. Stream lines coming from nozzle 1 are colored blue and the ones from nozzle 2 are colored red. One can see that the carrier gas stream flows quite straight into the outlet tube. Only a small fraction of the gas flows back into the chamber. The sample gas, in contrast, shows strong swirling flow structures. A large part of the flow enters at first the outlet tube and flows then back into the Venturi chamber. This behaviour has strong influence on the particle transport through this region.

In Fig. 8, particle tracks of particles with $100 \mathrm{~nm}, 500 \mathrm{~nm}$ and 1 $\mu \mathrm{m}$ diameter are shown. The particles were injected across the outlet of nozzle 1, having the same velocity as the gas. One can see that the particles with $1 \mu \mathrm{m}$ diameter are moving straight into the carrier gas stream and are nicely transported out of the cell. The particles of $100 \mathrm{~nm}$ follow quite well the flow lines and stay for some time captured in the vortices and are either lost to the

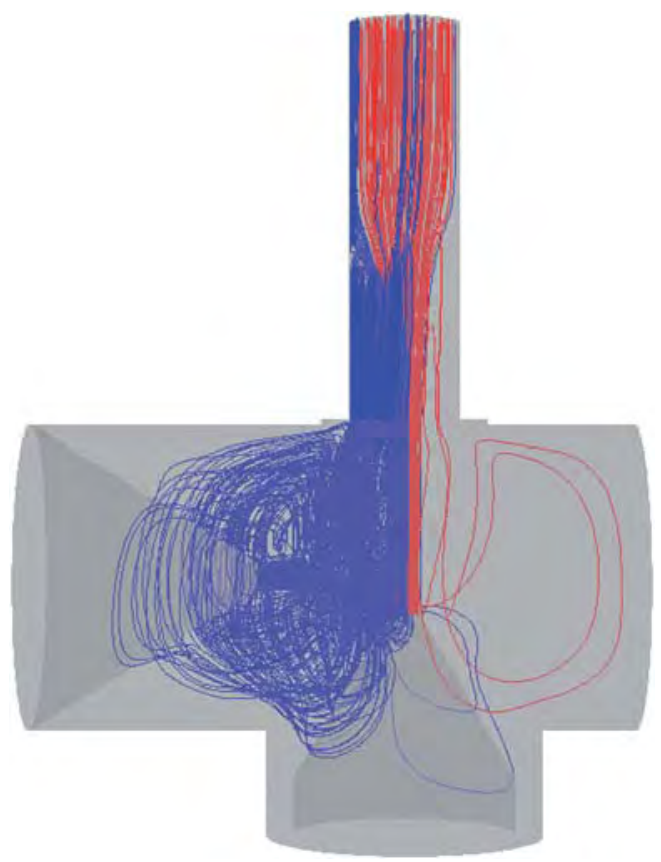

Fig. 7 Calculated stream lines inside the Venturi chamber for $100 \mathrm{~mL} /$ min helium introduced at nozzle 1 (left, blue) and $1.1 \mathrm{~L} / \mathrm{min}$ argon introduced at nozzle 2 (bottom, red).

wall or transported out of the cell, eventually. The particles of $500 \mathrm{~nm}$ diameter follow a mix of both types of behaviour. Some particles are transported straightly out of the cell while others return to the Venturi chamber.

In Fig. 9, the calculated transport efficiency through the Venturi chamber is plotted $v s$. the particle diameter for different sample gas flow rates. The carrier gas flow rate has been kept constant at $1.1 \mathrm{~L} / \mathrm{min}$ argon. 100000 particle packages have been tracked for each particle size. For low sample gas flow rates (below $50 \mathrm{~mL} / \mathrm{min}$ helium), a significant preferential loss of small particles was found. The transport efficiency was $55 \%$ for particles of $10 \mathrm{~nm}$ and a helium flow rate of $5 \mathrm{~mL} / \mathrm{min}$. It increased strongly with increasing diameter and reached more than $90 \%$ for particles bigger than $300 \mathrm{~nm}$. 

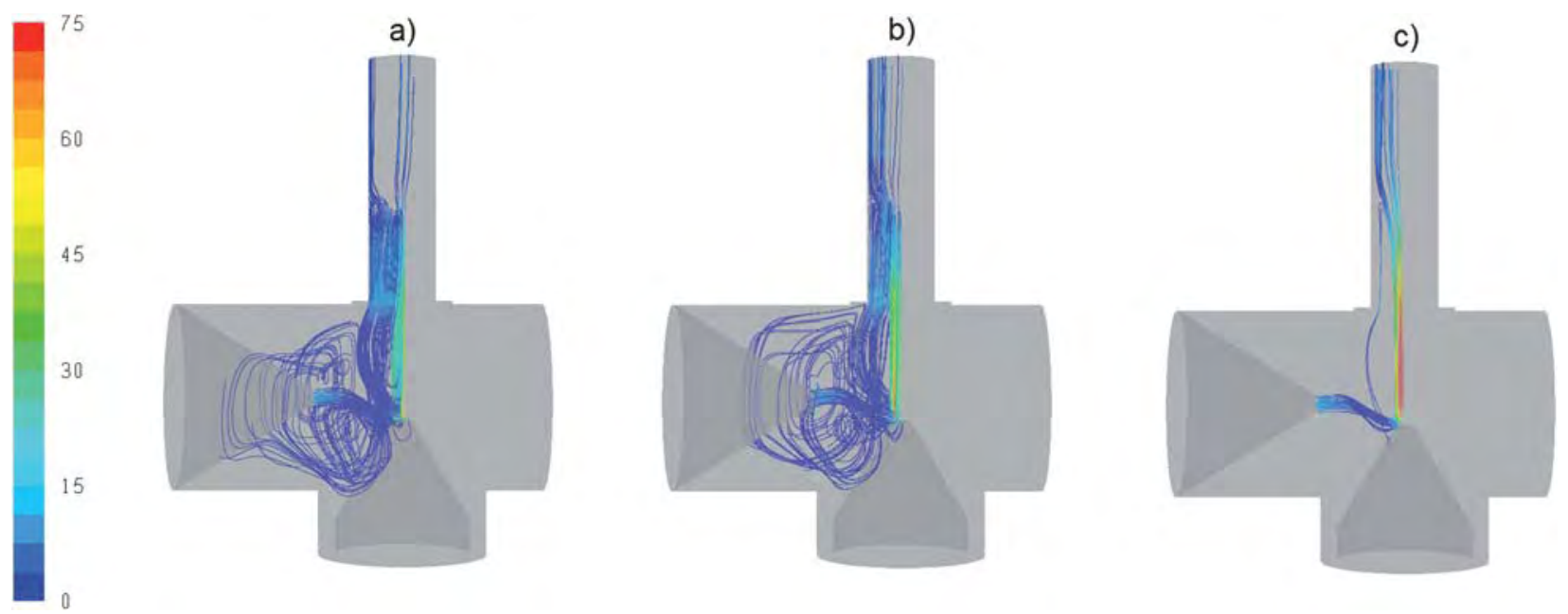

Fig. 8 Calculated particle tracks of particles of a) $100 \mathrm{~nm}$, b) $500 \mathrm{~nm}$ and c) $1 \mu \mathrm{m}$ diameter through the Venturi chamber at a sample gas flow rate of 100 $\mathrm{mL} / \mathrm{min}$ helium and a carrier gas flow rate of $1.1 \mathrm{~L} / \mathrm{min}$ argon. The tracks are colored by particle velocity in $\mathrm{m} / \mathrm{s}$.
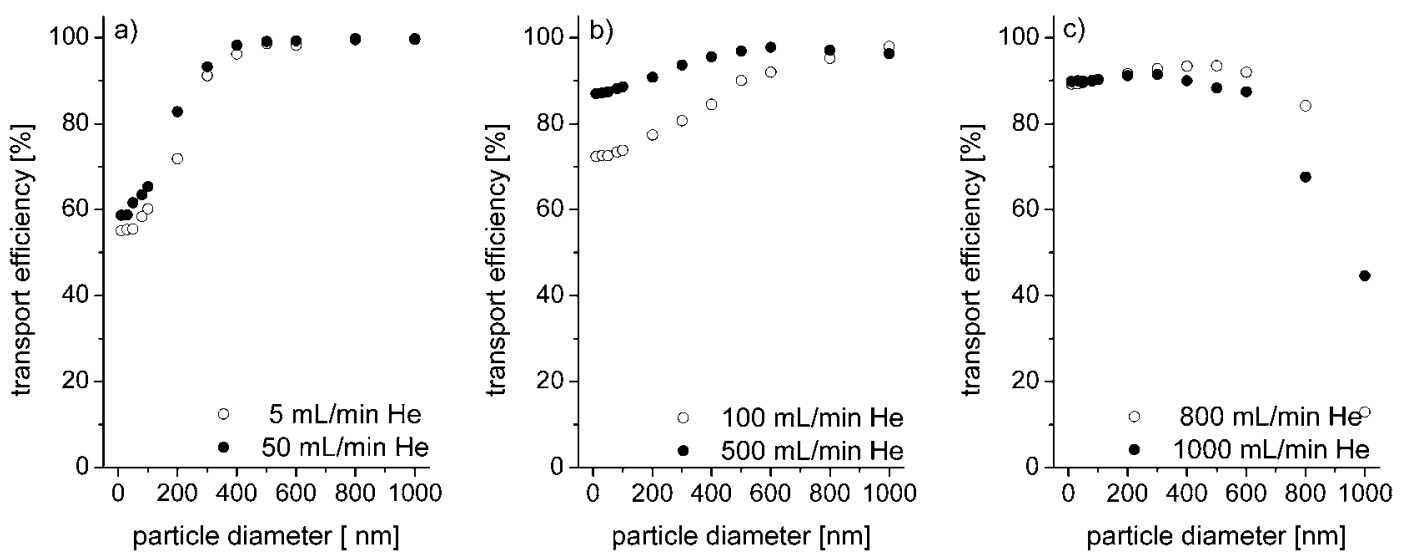

Fig. 9 Transport efficiency through the Venturi chamber vs. particle diameter for a) low, b) medium and c) high sample gas flow rates.

For medium helium flow rates $(\sim 100$ to $500 \mathrm{~mL} / \mathrm{min})$, the transport efficiency for small particles was higher $(72 \%$ for $100 \mathrm{~mL} / \mathrm{min} \mathrm{He}, 10 \mathrm{~nm}$ diameter). However, the slope for the transport efficiency with increasing diameter was lower. For $100 \mathrm{~mL} / \mathrm{min}$ helium, a transport efficiency of $85 \%$ was only reached for particles bigger than $400 \mathrm{~nm}$. A helium flow rate of $500 \mathrm{~mL} / \mathrm{min}$ provided a good transport efficiency for small and big particles (more than $87 \%$ ). However, small particles were still predominantly lost.

For high helium flow rates $(800 \mathrm{~mL} / \mathrm{min}$ and above), the preferential loss is exchanged to big particles. The transport efficiency was around $90 \%$ for small and medium sized particles ( $\leqq 600 \mathrm{~nm}$ in diameter) but it dropped below $45 \%$ for particles of $1 \mu \mathrm{m}$.

The preferential loss of larger particles for higher sample gas flow rates can be explained in the following way. Moving with about the same velocity as the gas, the particles have a higher momentum than at lower flow rates. Thus, when reaching the carrier gas, the particles do not stop directly inside the main carrier gas stream. They move somewhat through it and then similar effects take place for larger particles in the carrier gas stream as for small particles inside the sample gas stream.
The composition of laser produced particles is strongly size dependent. ${ }^{22,25,26}$ Therefore, the loss of any particles is disadvantageous. However, for fs-laser ablation, most particle mass is present in the particle size range below $500 \mathrm{~nm}$. Thus, the loss of larger particles has only little impact on the analytical result. This means, that higher sample gas flow rates are more appropriate for the Venturi stage than lower ones.

\subsection{Modified setup}

For the modified setup, three changes were made with respect to the original HEAD cell. The central chamber was replaced by a narrower tube-like chamber without cone, the Venturi chamber was removed and the carrier gas was introduced via the optional inlet, cp. Fig. 1. Behind the cell, a transport tube of $50 \mathrm{~cm}$ length and $2 \mathrm{~mm}$ inner diameter was placed.

In Fig. 10 flow lines are shown for gas flow rates of $1.1 \mathrm{~L} / \mathrm{min}$ argon (carrier gas) and $100 \mathrm{~mL} / \mathrm{min}$ helium (sample gas). The carrier gas was introduced from the side at the bottom of the central chamber. The sample is introduced by the sample gas stream in the bottom of the tube. The two gas streams flow concentrically and the sample gas stream is kept in the center of 


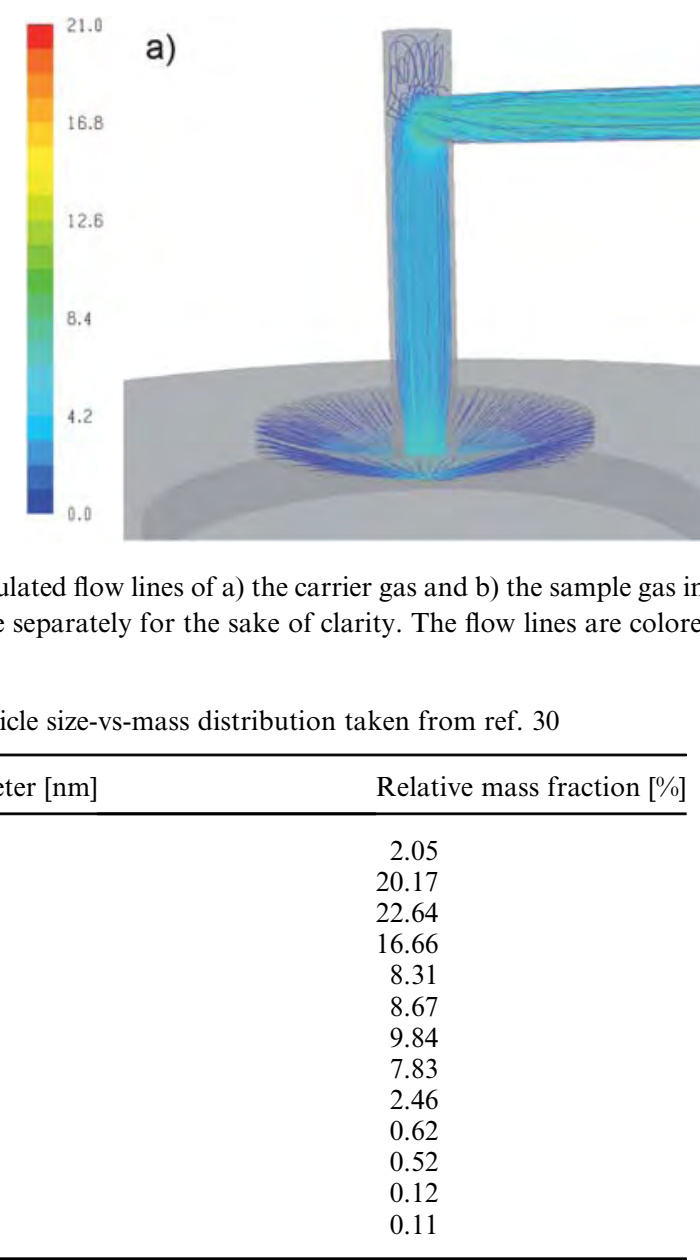

the tube (Fig. 10b). No back-flows occur in the central chamber and swirling structures are only present in the carrier gas at the top-side of the chamber. The sample gas flow lines are restricted to an area in the center of the tube. Since the particles follow mainly the flow lines, they are restricted too. Following the argumentation in ref. 13, this configuration should lead to very short washout times.

For reconstructing a signal, particles were released from the sample surface under an angle of 30 degrees. The velocity was set to $10 \mathrm{~m} / \mathrm{s}$ for a particle size of $1 \mu \mathrm{m}$. The other velocities were set according to the $d^{2}$-dependence displayed above, to obtain similar stop positions for all particle sizes. The velocity for the very small particles has been limited however. Indeed, the particles will not move faster than the laser produced shockwave. Initial speeds for shockwave of about $10000 \mathrm{~m} / \mathrm{s}$ have been found and predicted. ${ }^{27,28}$ Other measurements show shockwave speeds of around $2200 \mathrm{~m} / \mathrm{s}^{29}$ Therefore, an intermediate value for the initial particle velocity has been chosen, namely $5000 \mathrm{~m} / \mathrm{s}$. The particle mass-vs-size distribution (brass) was taken from ref. 30 and is given in Table 2.

In Fig. 11, the reconstructed signal is shown. As one can see, the signal's main duration was about $3 \mathrm{~ms}$. Particles up to $1 \mu \mathrm{m}$ diameter reached the outlet within $10 \mathrm{~ms}$ after start of the signal. This accounts for more than $99 \%$ of the introduced mass according to the used mass distribution. Large particles
Table 2 Particle size-vs-mass distribution taken from ref. 30

\begin{tabular}{lc}
\hline Particle diameter $[\mathrm{nm}]$ & Relative mass fraction $[\%]$ \\
\hline 6 & 2.05 \\
12 & 20.17 \\
22 & 22.64 \\
40 & 16.66 \\
72 & 8.31 \\
130 & 8.67 \\
230 & 9.84 \\
400 & 7.83 \\
650 & 2.46 \\
1050 & 0.62 \\
1700 & 0.52 \\
2700 & 0.12 \\
4300 & 0.11 \\
\hline
\end{tabular}

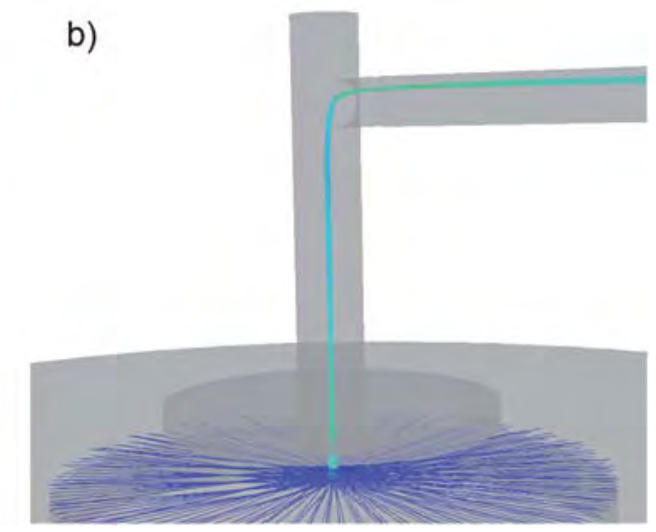

Fig. 10 Calculated flow lines of a) the carrier gas and b) the sample gas inside the modified cell. Both gas flows were present in both cases, but they are

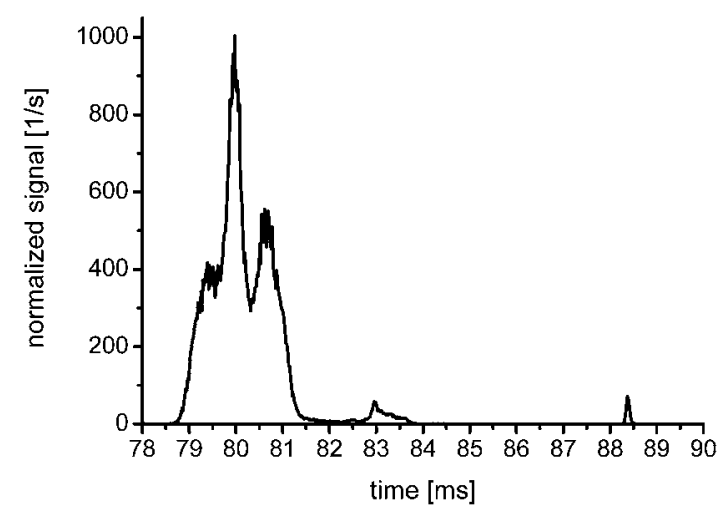

Fig. 11 Reconstructed signal for the modified cell; $100 \mathrm{~mL} / \mathrm{min}$ helium flowrate, $1.1 \mathrm{~L} / \mathrm{min}$ argon flowrate.

$(\gtrsim 2.7 \mu \mathrm{m})$ were lost at the bend from central chamber to outlet tube. Taking together all mass that reached the outlet, a transport efficiency of more than $99.7 \%$ was reached. For comparison, the already very short signal in ref. 13 had still a duration of 140 ms applying a $3 \%$ signal-area-criterion.

\section{Conclusions}

In laser ablation many particles are present as agglomerates, e.g. ref. 31,32. Thus, it would be interesting to compare the behaviour of single particles and agglomerates in the simulations. For that purpose, a reliable and sufficient statistical basis of the agglomerates is needed, such as binding strengths and size-distributions (of the single agglomerates and of the agglomerates in total). Unfortunately, these data are, to our knowledge, not available for laser produced aerosols. In the present simulations, the particles were tracked as single particles as we consider the effect of the agglomerates to be minor. Indeed, the agglomerate sizes are small compared to the dimensions of the flow system. Moreover, in ref. 25 it was stated that the laser produced agglomerates follow similar paths as the particles which the agglomerate consists of. Additionally, in our previous work, ${ }^{17}$ good agreement between simulation and experiment was found.

The different modular parts of the HEAD cell have been analysed by means of CFD. It was found that no significant 
particle losses occur at the ceiling of the sample chamber although the distance was only $0.8 \mathrm{~mm}$. This means that the arrangement of placing an orifice opposed to the ablation spot can be utilized expediently for laser ablation. The deceleration is produced by an effectively steady gas and not by the gas flow towards the ablation spot. Thus, the distance between sample and ceiling can, if wished, be increased to some extent without affecting the performance.

The gas in the sample chamber flows towards the center and focuses the ablated material to the cross-section of the orifice in the ceiling and pushes it through. This has been exploited in a modified arrangement of the HEAD cell where the aerosol is injected concentrically into the carrier gas stream. This central introduction results in a suppression of later particle losses during transport which we especially expect to be of interest when using long transport tubes. Additionally, the slowly flowing gas at the border of the tube does not affect the particle transport, resulting in a very short signal. Note that a laminar flow regime must be sustained within the whole route of transport, e.g. diverging tube parts need to be avoided. ${ }^{13,17}$ The calculated signal duration was found to be less than $10 \mathrm{~ms}$. Since no material flows with the slow velocity parts of the gas, a total washout can be achieved. To our knowledge, in all other setups, the whole transport tube cross-section is filled by the material, $c f$ ref. 13,15 .

For experiments, some considerations have to be taken into account when applying such short washout times. The main part of the signal was only $3 \mathrm{~ms}$. This is about the same as the duration of a signal produced by a single particle in ICP-OES. ${ }^{33}$ Consequently, it is very likely that the signal duration will be somewhat prolonged by effects taking place in the ICP. Furthermore, loading of the plasma may occur. Such effects should be investigated when analysing pulse-resolved signals. A very fast detector is required to resolve the signal for several elements and/or isotopes.

A pressure reduction device, such as the Venturi chamber is inevitable for an open non-contact cell. ${ }^{34}$ Otherwise, the sample gas does not effectively flow through the transport tubing but to the open. Significant losses can occur in the Venturi chamber depending on the sample gas flow rate. Therefore, calibrations for optimum transport should be performed prior to analysis. However, to be able to achieve better particle transport in a wider range of conditions, especially in terms of gas flow rates, the geometry of the Venturi chamber should be modified. The optimization needs to ensure that the sample gas flow is more efficiently introduced into the carrier gas flow and led into the transport tube.

\section{Acknowledgements}

Funding by the Flemish Fund for Scientific Research (FWO Vlaanderen) is gratefully acknowledged. Other financial support comes from the Federal Services for Scientific, Technical and Cultural Affairs (DWTC/SSTC) of the Prime Minister's Office through IUAP-VI. We thank the excellent calculation support of the core facility CALCUA, provided by the University of Antwerp. We also like to thank the machine shop at ETH Zurich for building the cell and providing the details about the dimensions for our calculations. Jorge Pisonero gratefully acknowledges
FICYT Project IB08-139 and "Ramon y Cajal" Research Program of the Ministry of Education of Spain, co-financed by the European Social Fund.

\section{References}

1 C. Dubuisson, A. G. Cox, C. W. McLeod, I. Whiteside, R. Jowitt and H. Falk, Characterisation of Inclusions in Clean Steels via Laser Ablation-ICP Mass Spectrometry, ISIJ Int., 2004, 44(11), 1859-1866.

2 S. Berends-Montero, W. Wiarda, P. de Joode and G. van der Peijl, Forensic analysis of float glass using laser ablation inductively coupled plasma mass spectrometry (LA-ICP-MS): validation of a method, J. Anal. At. Spectrom., 2006, 21, 1185-1193.

3 J. D. Woodhead, J. Hellstrom, J. M. Hergt, A. Greig and R. Maas, Isotopic and elemental imaging of geological materials by laser ablation inductively coupled plasma-mass spectrometry, Geostand. Geoanal. Res., 2007, 31(4), 331-343.

4 Q. Bian, C. C. Garcia, J. Koch and K. Niemax, Non-matrix matched calibration of major and minor concentrations of $\mathrm{Zn}$ and $\mathrm{Cu}$ in brass, aluminium, and silicate glass using NIR femtosecond laser ablation inductively coupled plasma mass spectrometry, J. Anal. At. Spectrom., 2006, 21, 187.

5 L. Halicz and D. Günther, Quantitative analysis of silicate glasses using LA-ICP-MS with liquid calibration, J. Anal. At. Spectrom., 2004, 19, 1539-1545.

6 A. Polatajko, M. Azzolini, I. Feldmann, T. Stuezel and N. Jakubowski, Laser ablation-ICP-MS assay development for detecting $\mathrm{Cd}$ - and $\mathrm{Zn}$-binding proteins in Cd-exposed Spinacia oleracea L., J. Anal. At. Spectrom., 2007, 22, 878-887.

7 V. Kanický, H. R. Kuhn and D. Günther, Depth profile studies of ZrTiN coatings by laser ablation inductively coupled plasma mass spectrometry, Anal. Bioanal. Chem., 2004, 380, 218-226.

8 C. C. Garcia, H. Lindner and K. Niemax, Laser ablation inductively coupled plasma mass spectrometry-current shortcomings, practical suggestions for improving performance, and experiments to guide future development, J. Anal. At. Spectrom., 2009, 24, 14-26.

9 J. Pisonero and D. Günther, Femtosecond laser ablation inductively coupled plasma mass spectrometry: fundamentals and capabilities for depth profiling analysis, Mass Spectrom. Rev., 2008, 27, 609-623.

10 C. C. Garcia, H. Lindner and K. Niemax, Transport efficiency in femtosecond laser ablation inductively coupled plasma mass spectrometry applying ablation cells with short and long washout times, Spectrochim. Acta, Part B, 2007, 62, 13-19.

11 C. C. Garcia, M. Wälle, H. Lindner, J. Koch, K. Niemax and D. Günther, Femtosecond laser ablation inductively coupled plasma mass spectrometry: Transport efficiencies of aerosols released under argon atmosphere and the importance of the focus position, Spectrochim. Acta, Part B, 2008, 63, 271-276.

12 E. L. Gurevich and R. Hergenröder, A simple laser ICP-MS ablation cell with wash-out time less than $100 \mathrm{ms,}$, Anal. At. Spectrom., 2007, 22, 1043-1050.

13 H. Lindner, D. Autrique, C. C. Garcia, K. Niemax and A. Bogaerts, Optimized Transport Setup for High Repetition Rate Pulse-Separated Analysis in Laser Ablation-Inductively Coupled Plasma Mass Spectrometry, Anal. Chem., 2009, 81, 4241-4248.

14 J. Pisonero, D. Fliegel and D. Günther, High efficiency aerosol dispersion cell for laser ablation-ICP-MS, J. Anal. At. Spectrom., 2006, 21, 922-931.

15 J. Koch, M. Wälle, R. Dietiker and D. Günther, Analysis of LaserProduced Aerosols by Inductively Coupled Plasma Mass Spectrometry: Transport Phenomena and Elemental Fractionation, Anal. Chem., 2008, 80, 915-921.

16 D. Bleiner and A. Bogaerts, Computer simulations of sample chambers for laser ablation-inductively coupled plasma spectrometry, Spectrochim. Acta, Part B, 2007, 62, 155-168.

17 D. Autrique, A. Bogaerts, H. Lindner, C. C. Garcia and K. Niemax, Design analysis of a laser ablation cell for inductively coupled plasma mass spectrometry by numerical simulation, Spectrochim. Acta B, 2008, 63, 257.

18 J. Pisonero, J. Koch, M. Wälle, W. Hartung, N. D. Spencer and D. Günther, Capabilities of femtosecond laser ablation inductively 
coupled plasma mass spectrometry for depth profiling of thin metal coatings, Anal. Chem., 2007, 79, 2325-2333.

19 W. C. Hinds Aerosol technology John Wiley \& Sons, 2nd edition, 1999.

20 ANSYS Fluent 6.3 Users Guide, Fluent Inc., 2006.

21 D. J. Figg, J. B. Cross and C. Brink, More investigations into elemental fractionation resulting from laser ablation-inductively coupled plasma-mass spectrometry on glass samples, Appl. Surf. Sci., 1998, 127-129, 287-291.

22 J. Koch, A. von Bohlen, R. Hergenröder and K. Niemax, Particle size distributions and compositions of aerosols produced by near-IR femto- and nanosecond laser ablation, J. Anal. At. Spectrom., 2004, 19, 267.

23 R. Jaworski, E. Hoffmann and H. Stephanowitz, Collection and separation of particles by size from laser ablated material, Int. J. Mass Spectrom., 2002, 219, 373-379.

24 J. Koch, S. Schlamp, T. Rösgen, D. Fliegel and D. Günther, Visualization of aerosol particles generated by near infrared nanoand femtosecond laser ablation, Spectrochim. Acta, Part B, 2007, 62, 20-29.

25 J. Koch, H. Lindner, A. von Bohlen, R. Hergenröder and K. Niemax, Elemental fractionation of dielectric aerosols produced by nearinfrared femtosecond laser ablation of silicate glasses, J. Anal. At Spectrom., 2005, 20, 901.

26 C. Liu, X. Mao, S. S. Mao, R. Greif and R. E. Russo, Particle Size Dependent Chemistry from Laser Ablation of Brass, Anal. Chem. 2005, 77(20), 6687-6691.
27 V. Margetic, T. Ban, F. Leis, K. Niemax and R. Hergenröder, Hydrodynamic expansion of a femtosecond laser produced plasma, Spectrochim. Acta, Part B, 2003, 58, 415-425.

28 A. Bogaerts, Z. Chen and D. Bleiner, Laser ablation of copper in different background gases: comparative study by numerical modeling and experiments, J. Anal. At. Spectrom., 2006, 21, 384-395.

29 R. E. Russo, X. L. Mao, C. Liu and J. Gonzalez, Laser assisted plasma spectrochemistry: laser ablation, J. Anal. At. Spectrom., 2004, 19, 1084-1089.

$30 \mathrm{H}$. Lindner "Untersuchungen zur Partikelverteilung und -zusammensetzung beim Laserabtrag" Diplomarbeit Universität Dortmund, Germany, 2004.

31 C. Liu, X. L. Mao, S. Mao, X. Zeng, R. Greif and R. E. Russo, Nanosecond and Femtosecond Laser Ablation of Brass: Particulate and ICPMS Measurements, Anal. Chem., 2004, 76, 379-383.

32 H. R. Kuhn, J. Koch, R. Hergenröder, K. Niemax, M. Kalberer and D. Günther, Evaluation of different techniques for particle size distribution measurements on laser-generated aerosols, J. Anal. At. Spectrom., 2005, 20, 894-900.

33 M. Miclea, C. C. Garcia, I. Exius, H. Lindner and K. Niemax, Emission spectroscopic monitoring of particle composition, size and transport in laser ablation inductively coupled plasma spectrometry, Spectrochim. Acta, Part B, 2006, 61, 361 .

34 D. Asogan, B. L. Sharp, C. J. P. O'Connor, D. A. Green and R. W. Hutchinson, An open, non-contact cell for laser ablationinductively coupled plasma-mass spectrometry, J. Anal. At. Spectrom., 2009, 24, 917-923. 